\title{
Constraints and Management Practices of Dairy Farming during COVID-19 Pandemic Situation
}

\author{
K.P. Saravanan, P. Silambarasan', A. Manivannan, V. Sasikala, T. Sivakumar
}

10.18805/ajdfr.DR-1620

\begin{abstract}
Background: The COVID-19 pandemic and subsequent lockdown have created unprecedented emergency and sudden distress on all sectors in India including the livestock sector. Among livestock sectors, dairy farming is more sensitive due to the handling of an essential and perishable commodity of milk.

Methods: Under this pandemic situation, the aim of the study to know the constraints confronted and management practices followed by dairy farmers during the COVID-19 pandemic situation. The study was conducted in July 2020 in Cuddalore district of Tamil Nadu. Thirty dairy farmers were selected randomly and data were collected by a personal interview method through a well-structured interview schedule. Socio-economic data were analyzed by statistical methods viz. percentage, mean and standard deviation. Constraints of dairy farming were analyzed and ranked by Mean Weighed Score method and percentage analysis was used for analyzing and ranking management practices.

Result: Socio-economic characterstics revealed that more than 86.66 per cent of dairy farmers were belonged low to medium groups and utilized different mass media tools for retrieving information. The constraints analysis revealed that high cost of concentrate feed foremost constraint with Mean Weighed Score of 50.00 were ranked first. Dairy farmers expressed difficultly in the procurement of concentrate, shortage of wheat bran supply and elevated wheat bran cost (MWS 44.44) second important constraints. Dairy farmer's made alterations in the concentrate feed composition, consulted veterinary doctors over the phone and direct selling of milk as management practices to manage the pandemic situation.
\end{abstract}

Key words: Constraints, COVID-19, Dairy.

\section{INTRODUCTION}

Livestock rearing is an important livelihood activity for economically weaker sections of the society. The COVID 19 induced pandemic in India has forced the Government of India to impose lockdown from March 2020 onwards. Crop, livestock and fisheries have been affected by this pandemic (Popat et al., 2020; Poudel et al., 2020). Further farmers were not prepared and unaware of this sudden closure of all pathways. Generally, farmers prepare well in advance for any kind of distress since lack of prior exposure and knowledge about the lockdown uncertainty looms over among the farming community and dairy farming no exception (Palsaniya, 2020). Sudden closure of all institutes, both government and private due to the pandemic, farmers have been unable to meet the emergent situation at ground level. Under these circumstances, the study was formulated with the objectives of identifying constraints confronted and management practices followed by dairy farmers during the COVID-19 lockdown period.

\section{MATERIALS AND METHODS Study area}

The present study was conducted in Cuddalore district of Tamil Nadu, India since the district possesses huge potential of dairy farming. The district is predominantly involved agricultural and allied sector activities. The total geographical area of the district is 3678 sq. $\mathrm{km}$ with the coastal line of 68
Department of Veterinary and Animal Husbandry Extension Education, Veterinary College and Research Institute, Veterinary and Animal Sciences University, Orathanadu-614 625, Thanjavur, Tamil Nadu, India.

'Veterinary University Training and Research, Cuddalore-607 001, Tamil Nadu, India.

Corresponding Author: K.P. Saravanan, Department of Veterinary and Animal Husbandry Extension Education, Veterinary College and Research Institute, Veterinary and Animal Sciences University, Orathanadu-614 625, Thanjavur, Tamil Nadu, India.

Email: k.p.saravananvet@gmail.com

How to cite this article: Saravanan, K.P., Silambarasan, P., Manivannan, A., Sasikala, V. and Sivakumar, T. (2021). Constraints and Management Practices of Dairy Farming during COVID-19 Pandemic Situation. Asian Journal of Dairy and Food Research. 40(1): 20-24. DOI: 10.18805/ajdfr.DR-1620.

Submitted: 02-01-2021 Accepted: 05-02-2021 Online: 06-03-2021

$\mathrm{kms}$. The average annual rainfall is $1206.7 \mathrm{~mm}$ major rainfall received during North-East monsoon only (https:// cuddalore.nic.in/animal-husbandry/).

\section{Methods of sampling and research design}

A total of 30 respondents consisting of dairy farmers in Cuddalore district of Tamil Nadu were selected randomly for the study. An expost-facto research design was followed for conducting the study. The primary data was collected 


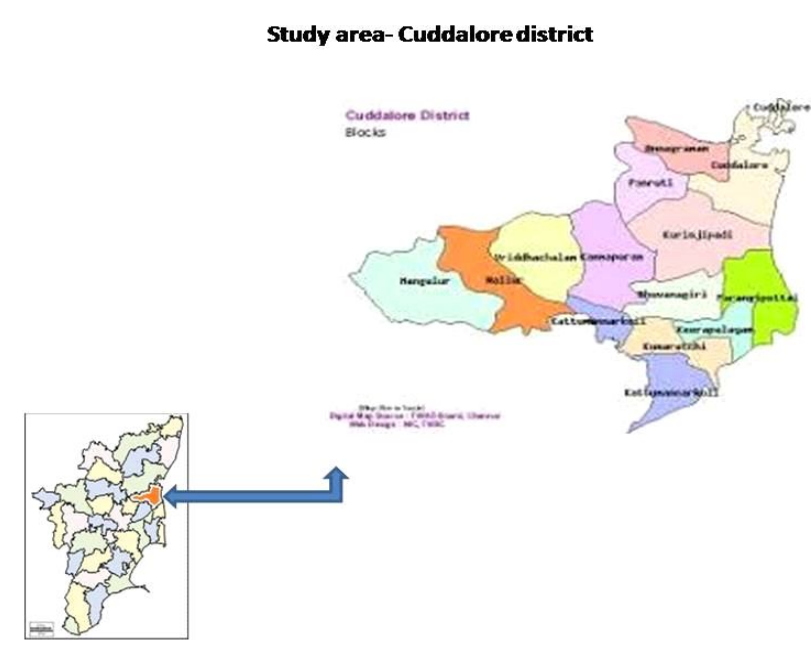

Fig 1: Study area.

Table 1: Socio-economic variables and measurements.

\begin{tabular}{lll}
\hline S.No. & Variables & Measurement \\
\hline$X_{1}$ & Age & Numbers (in completed years) \\
$X_{2}$ & Sex & Categorical (M/F) \\
$X_{3}$ & Type of family & Categorical (Yes/No) \\
$X_{4}$ & Education & Number of years \\
$X_{5}$ & Land holding & Acers \\
$X_{6}$ & Farming experience & Years \\
$X_{7}$ & Occupation & Categorical (Yes/No) \\
$X_{8}$ & Livestock possession & Numbers \\
$X_{9}$ & Mass media participation & Mean \\
\hline
\end{tabular}

through an interview schedule from the dairy farmers in the month of July 2020 .

\section{Statistical analysis}

Primarily to know about the socio-economic characteristics of dairy farmers during the pandemic situation, nine socioeconomic variables were included in the study and interpreted with percentage, mean and standard deviation.

\section{Constraint analysis}

Key informant technique, secondary literature and expert consultation were used to identify and collect the list of constraints encountered by the respondents. To identify the degree of constraints faced by dairy farmers during COVID19 lockdown three-point continuum scale was used and scores were given 3,2,1 for most serious, serious, not serious respectively. The important constraints were identified by comparing their weighted mean score and ranking was also done based on their weighted mean score (Meena et al., 2018).

Weighted mean score $=$

$$
\begin{aligned}
& \text { Total score obtained of all members in } \\
& \text { each item of constraints } \\
& \text { Total maximum possible score for each } \\
& \text { item of constraints }
\end{aligned}
$$

\section{Analysis of management practices}

Based on key informant interview and expert consultation management practices were identified in three dimensions namely feeding, disease management and marketing. The management practices followed during COVID-19 pandemic situation by the respondents were given the score of 1 and 0 for followed or not-followed categories respectively. Based on obtained scores percentage analysis was done and ranked the management practices.

\section{RESULTS AND DISCUSSION Socio-economic characteristics}

Table 2 reveals that the dairy farmer's socio-economic characteristics during COVID-19 lockdown. In the study area, more than half of the respondents (56.67) were middle age group and other farmers were belonged to young and old age group. The mean age of farmer was 40 . It reveals middle age group farmers could be able to handle an unexpected situation in an efficient way. Further Table 2 reveals that the majority of the farmers were male and in a joint family. More than one-third (54.00 per cent) of the respondents were studied upto $10^{\text {th }}$ followed by nearly onethird (36.67per cent) of the respondents who had collegiate levels of education and the rest of the farmers had primary and higher secondary. Gopi et al. 2020 reported that 36.70 per cent of farmers were illiterate.

It further reveals that only 16.67 per cent of farmers were landless and more than two-third (66.67percent) of the respondents were marginal and small farmers. Remaining 12.00 per cent were large farmers. Gopi et al., 2020 also reported that nearly half $(46.70)$ of the dairy farmers were small and marginal categories. Holding land during emergency and crisis periods would provide supplementary support for cultivating fodder and agriculture. Majority (76.67 per cent) of the farmers were possessed dairy alone as the main occupation and the remaining respondents were rearing dairy and other livestock. It indicates that possession of dairy during the emergency period's an important means for sustainable livelihood.

More than 86.66 per cent of dairy farmers have belonged to low to medium group of mass media participation and the rest of them had a high level of mass media participation (13.33 per cent). Gopi et al. 2020 also reported that similar kindly information-seeking behaviour (85.00 per cent). During the pandemic, situation farmers were assessed by different regional tamil mass media sources viz, kalnadai kathir, pasumai vikadan, youtube videos of dairy farmers, breeding males, naveena uzhavar iyarkai vivasayam, vivasaya nanban, pasumai vivasayam and WhatsApp group of nattukozhi valarppu, nadappena sei, kalnadai valarppu thakaval maiyam MS Swaminathan research foundation for retrieving livestock farming information. This indicates that dairy farmers were spent a good amount of time for availing livestock information. 
Table 2: Distribution of dairy farmer according to their socio-economic profile $\mathrm{N}=30$.

\begin{tabular}{|c|c|c|c|c|}
\hline Variables & Socio-economic characteristics & Numbers & Percentage & Mean \\
\hline & Age & & & \\
\hline & Young (Below 35) & 11 & 36.67 & \\
\hline \multirow[t]{3}{*}{$x_{1}$} & Middle age (35-60) & 17 & 56.67 & 40 \\
\hline & Old (above 60) & 2 & 6.67 & \\
\hline & Sex & & & \\
\hline \multirow[t]{3}{*}{$\mathrm{X}_{2}$} & Male & 28 & 93.33 & \\
\hline & Female & 2 & 6.67 & \\
\hline & Type of family & & & \\
\hline \multirow[t]{4}{*}{$\mathrm{x}_{3}$} & Nuclear & 8 & 26.67 & \\
\hline & Joint & 22 & 73.33 & \\
\hline & Education & & & \\
\hline & Primary & 2 & 6.67 & \\
\hline \multirow[t]{5}{*}{$X_{4}$} & Secondary & 12 & 40.00 & \\
\hline & Higher secondary & 5 & 16.67 & \\
\hline & UG/Diploma & 11 & 36.67 & \\
\hline & Land holding & & & \\
\hline & Landless ( 0 acres) & 5 & 16.67 & \\
\hline \multirow[t]{5}{*}{$X_{5}$} & Marginal (0.01 to 2.5 acres) & 11 & 36.67 & 3.62 \\
\hline & Small ( 2.5 to 5 acres) & 9 & 30.00 & \\
\hline & Large (more than 5 acres) & 4 & 13.33 & \\
\hline & Farming experience & & & \\
\hline & Upto 10 Years & 13 & 43.33 & \\
\hline \multirow[t]{3}{*}{$X_{6}$} & 10 to 20 Years & 11 & 36.67 & 20.43 \\
\hline & Above 20 Years & 16 & 53.33 & \\
\hline & Occupation & & & \\
\hline \multirow[t]{3}{*}{$x_{7}$} & Primary (Dairy main) & 11 & 36.67 & \\
\hline & Secondary & 19 & 63.33 & \\
\hline & Livestock possession & & & \\
\hline \multirow[t]{4}{*}{$\mathrm{X}_{8}$} & Dairy only & 23 & 76.67 & 11.3 \\
\hline & Dairy and other livestock & 7 & 23.33 & \\
\hline & Mass media participation & & & \\
\hline & Low & 19 & 63.33 & \\
\hline \multirow[t]{2}{*}{$X_{9}$} & Medium & 7 & 23.33 & 5.46 \\
\hline & High & 4 & 13.33 & \\
\hline
\end{tabular}

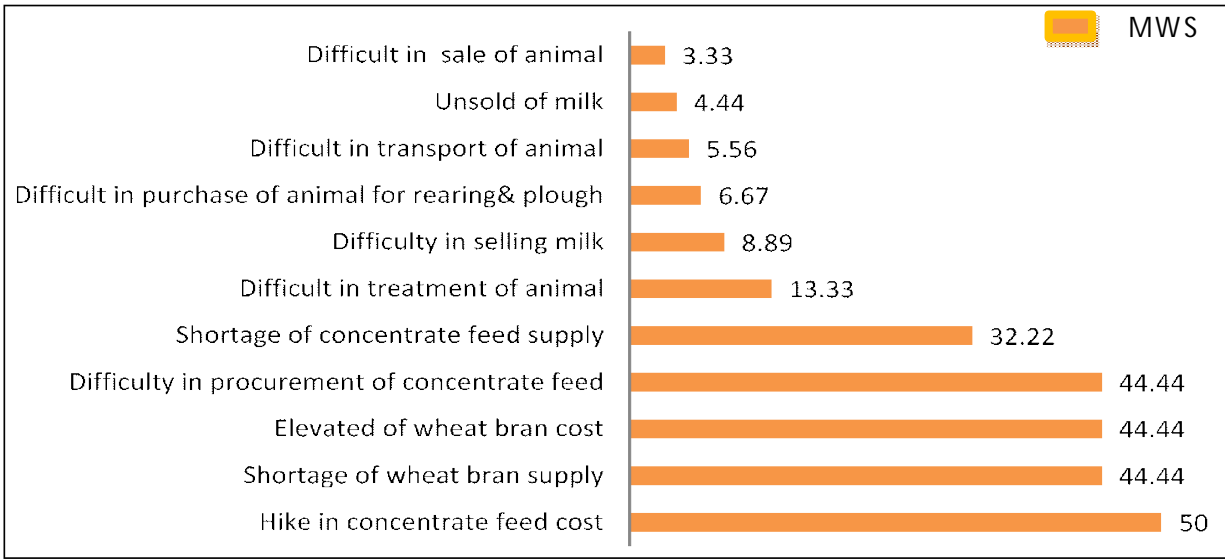

Fig 2: Constraints confronted by dairy farmers during lockdown. 


\section{Constraint confronted by dairy farmers during lockdown}

The result presented in Fig 2 revealed that the high cost of concentrate feed with mean weighed score of 50.00 was ranked first as a major problem in dairy farming. Compare to before lockdown the cost of concentrate feed was increased by Rs. 2 to $3 /$ per $\mathrm{kg}$ of feed leads to an increase in production cost. This is mainly due to the unavailability of concentrate feed ingredients, logistics difficult. The farmers also expressed that shortage of wheat bran supply, the elevation of wheat bran cost and difficulty in the procurement of concentrate second important constraints with MWS of 44.44 during the pandemic situation and shortage of concentrate supply. Wheat bran cost also elevated by Rs 2 to $3 /$ - wheat bran important ingredient which directly affected the farmers income.

In disease aspects difficult in the treatment of an animal with MWS of 13.33, other impediments such as difficulty in selling milk, difficulty in purchase and sale of animal for rearing and plouging, difficulty in the transport of animal, unsold milk were found other constraints. Prathibha et al., 2020 reported that women dairy entrepreneurs in the Puducherry district were also faced hurdles of high feed cost, reduced milk price, lack of market during the lockdown.

Poudel et al., 2020 acknowledged that the lockdown disturbed the supply chain of the market with weakens production with a lack of inputs supply and labour. Manivannan et al., 2018 concluded unavailability of veterinary treatment facilities an important problem during vagaries of nature.

\section{Management practices followed during COVID-19 Feeding practices followed}

The management practices followed in dairy farming by the respondent was presented in Table 3 along with respective ranking. The practices were grouped into three heading namely feeding, disease management and marketing management practices in dairy farming.

More than slightly one-third of respondents (40.00) altered the composition of concentrate feeding ranked as first as a way to overcome the constraints such as high cost of concentrate and wheat bran cost. Before lockdown, respondents were using the homemade concentrate for feeding milch animals. Based on the availability of local ingredients and they modified feed composition and changed two or three ingredients in concentrate. They followed this kind of feeding practices namely; a) Rice bran, wheat bran and red gram powder b) Wheat bran, rice bran cotton seed cake, ground nut cake c) Wheat bran, groundnut cake and tapioca powder d) Groundnut cake alone e) Mixture of concentrate feed and tapioca powder f) Concentrate feed and rice bran, wheat bran, rice cruel e) Groundnut cake and green gram g) Wheat bran, rice bran, black gram, green gram, corn flour, tapioca powder, broken rice and salt $h$ ) Wheat bran, commercial concentrate, corn flour and ground nut cake i) Wheat bran, rice bran, red gram sesame oil cake, corn flour and ground nut cake during lockdown.
Further, Table 3 shows that 23.33 percentage of farmers were increased their grazing duration and ranked II. They increased two to three hours of grazing period and managed a shortage of concentrate supply and maintain production level. Experienced farmers, integrated farmers and large dairy farmers have utilized buffer stock of feed, maintained their animal by providing straw and dry fodders. They were mainly stocked up the black gram, rice bran, red gram and groundnut hay.

Integrated farmers, experienced farmers decreased grazing duration (IV). Nearly they reduced grazing time for two hours per day and followed intensive rearing due to fear of pandemic. 10.00 per cent of farmers changed grazing place, increased utilization of rice bran and decreased utilization of wheat bran. Among the feed ingredients, farmers mainly utilizing wheat bran is an important ingredient because it provides a pleasant aroma and soft leads to increase the thirst for voluntary intake and helpful for increasing milk yield. Due to unavailability and high cost of wheat at the time of lockdown farmers were used rice bran.

\section{Disease management practices followed}

A majority (80.00) of the dairy farmers consulted veterinary doctors over the phone for getting assistance especially

Table 3: Feeding practices followed during COVID-19. N=30.

\begin{tabular}{lcc}
\hline \multirow{2}{*}{ Feeding practices } & \multicolumn{2}{c}{ During lockdown } \\
\cline { 2 - 3 } & Percentage & Rank \\
\hline Altered the composition of concentrate feeding & 40.00 & $\mathrm{I}$ \\
Increased grazing time & 23.33 & $\mathrm{II}$ \\
Utilized buffer stock of feed & 20.00 & $\mathrm{III}$ \\
Decreased grazing duration & 13.33 & $\mathrm{IV}$ \\
Increased utilization of rice bran & 10.00 & $\mathrm{~V}$ \\
Decreased utilization of wheat bran & 10.00 & $\mathrm{~V}$ \\
Changed grazing place & 10.00 & $\mathrm{~V}$ \\
Utilization of Azolla & 10.00 & $\mathrm{~V}$ \\
Increased utilization of alternative feed & 6.67 & $\mathrm{VI}$ \\
resources (Sugarcane tops, Banana leaves) & &
\end{tabular}

Table 4: Disease management practices followed during COVID19. $\mathrm{N}=30$.

\begin{tabular}{lcc}
\hline \multirow{2}{*}{ Disease management } & \multicolumn{2}{c}{ During lockdown } \\
\cline { 2 - 3 } & Percentage & Rank \\
\hline Consulted Veterinary Doctors through telephone & 80.00 & 1 \\
Followed herbal veterinary treatment & 26.67 & II \\
Utilized youtube video for treatment & 20.00 & III \\
Utilized social media messages for treatment & 3.33 & IV \\
\hline
\end{tabular}

Table 5: Marketing practices followed during COVID-19. $\mathrm{N}=30$.

\begin{tabular}{lcc}
\hline \multirow{2}{*}{ Marketing practices } & \multicolumn{2}{c}{ During lockdown } \\
\cline { 2 - 3 } & Percentage & Rank \\
\hline Direct selling of milk & 53.33 & I \\
Preparation of valued added dairy products & 16.67 & II \\
like curd, paneer & & \\
Alteration the location of milk selling place & 10.00 & III \\
\hline
\end{tabular}


bloat, enteritis, acidosis conditions since veterinary doctors as trusted sources for providing veterinary care services during emergency situations ranked as first. Saravanan et al., 2020 in their study also concluded that veterinarian doctor was an important information source during the crisis. Nearly 26.67 respondents were followed herbal veterinary treatment based on their previous experience and consulting with other progressive farmers in the village.

The following herbal treatments such as application of turmeric, kuppaimeni leaves, neem leaves, turmeric, karporam, kalyanamurungai for pox infection, sodium bicarbonate for bloat were followed. Educated and young farmers have viewed youtube videos (20.00) for primary health care treatment and livestock farming. Only a meager number of farmers utilized social media since it is not authenticated source, so they did not avail much.

\section{Marketing practices followed}

In the study area, more than half of them were sold their milk directly to consumers (Rank I) because of the low price for milk, unsold milk and high cost of concentrate were craved towards direct selling. Women entrepreneurs in Puducherry district were $13.33 \%$ sold to directly, $66.67 \%$ were sold to co-operative society $13.33 \%$ and $20 \%$ cooperative society and consumers during the lockdown (Prathibha et al. 2020).

Large dairy farmers and those farmers unable to sell milk directly have prepared value-added dairy products (II) like curd, ghee, rosemilk and badam milk. 10 per cent of farmers changed their location of selling due to non remunerative price for the milk. They changed location from selling privately to Aavin, direct sale to consumers; government to private depends upon the speedy acceptance and price.

\section{CONCLUSION}

The current pandemic situation is unexpected although results were indicating that dairy farmers were managing their farm based on their experience, traditional knowledge, animal husbandry emergency services and social media. Even though they were lacking in other means viz., utilizing non-conventional fodder, green fodder cultivation and preparation of value-added products. The findings of the study would be helpful in formulating pertinent training and sensitization programmes by Government in the time of the extremely unexpected situation.

\section{ACKNOWLEDGEMENT}

The authors sincerely acknowledge the facilities provided by the Vice-Chancellor, Tamil Nadu Veterinary and Animal Sciences University, Chennai for carrying out this research study.

\section{REFERENCES}

Cuddalore district profile .https://cuddalore.nic.in/animal-husbandry/ accessed on 29.09.2020.

Gopi, R., Manivannan, A, Sindhu, M.G. and Soundararajan, C. (2020). Socio-economic profile and constraints of dairy farmers in Cuddalore district of Tamil Nadu, India. International Journal of Current Microbiology and Applied Science. 9(4): 1320-1326. doi: https://doi.org/10.20546/ ijcmas.2020.904.15.

Manivannan, A., Sivakumar, T., Saravanan, K.P. and Sakthivel, K.M. (2018). Constraints encountered in Livestock Farming in the aftermath of Gaja Cyclone at Thanjavur District, Tamil Nadu. International seminar on Innovative Extension Management for uplifting livelihood of farmers - Status, Initiatives and Way forward. 357-361.

Meena, O.P., Sharma, N.K., Jeph, N.K. and Meena, D.S. (2018). Constraints perceived by dairy members in adoption of new technologies in dairy farming in Rajasthan. Veterinary Practitioner. 19(2): 317-319.

Palsaniya, D.R. (2020). Researchable issues in livestock and fodder sector under COVID-19 pandemic and beyond. Current Science. 118(12): 1865-1866.

Popat, S.J., Ashish, R., Kadam, S. and Mane, S.P. (2020). Effects of COVID-19 on dairy farming. Juni Khyat. 10 (6): 16-30.

Poudel, P.B., Poudel, M.R., Gautam, A., Phuyal, S., Tiwari, C.K., Bashyal, N. and Bashya, S. (2020). COVID-19 and its Global Impact on Food and Agriculture. Journal of Biology and Today's World. 9(5).

Prathibha, A.I., Bhanu Rekha, V., Ajay Kuma, V.J., Nithya Quintoil, M. and Sowmiya, V. (2020). Assessment of hurdles faced by women entrepreneurs in livestock sector during COVID 19 Lockdown. International Journal of Current Microbiology and Applied Science. 9(7): 3033-3039. doi: https://doi.org/ 10.20546/ijcmas.2020.907.357.

Saravanan, K.P., Manivannan, C., Sudeep Kumar, N.K. and Kathiravan, G. (2020). Crisis Management Practices Employed by Sheep Farmers to Overcome the Crisis in Sheep Farming in Erode District of Tamil Nadu. International Journal of Livestock Research. 10(5): 106-113. 